\title{
Cognitive anosognosia and behavioral changes in probable Alzheimer's disease patients
}

\author{
Corina Satler ${ }^{1}$, Carlos Tomaz ${ }^{2}$
}

\begin{abstract}
Anosognosia, impairment insight and unawareness of deficits are used as equivalent terms in this study. Objective: To investigate the relationship between the presence of anosognosia symptoms and cognitive domains, functional abilities, and neuropsychiatric symptoms in patients with probable Alzheimer's disease (PAD) and elderly controls (EC). Methods: Twenty-one pAD (14 women) and twenty-two EC (16 women) were submitted to a neuropsychological battery of tests assessing global cognitive status, and specific cognitive functions: memory, executive and attention functions, verbal fluency and visuoconstructive abilities. Additionally, functional abilities (FAQ) and neuropsychiatric symptoms (NPI) were measured. Results: The linear regression statistical test found general anosognosia to be associated with subjective memory complaints, age and Arithmetic-DRS in the EC group. On the other hand, cognitive and functional abilities scores (ArithmeticDRS, IQCODE and FAQ) were the best predictors in PAD patients, particularly for behavioral awareness. Conclusion: These results indicated that different variables are associated with self-awareness for pAD patients and EC, but for both groups executive functions appear to play an important role, contributing particularly to awareness of behavioral changes.
\end{abstract}

Key words: awareness, anosognosia, insight, aging, Alzheimer's disease, dementia.

\section{ANOSOGNOSIA COGNITIVA E ALTERAÇ̃̃ES COMPORTAMENTAIS EM PACIENTES COM PROVÁVEL DOENÇA DE ALZHEIMER}

RESUMO. Anosognosia, comprometimento do insight e ausência de reconhecimento de déficits são usados como termos equivalentes neste estudo. Objetivo: Investigar a relação entre a presença de sintomas de anosognosia e domínios cognitivos, habilidades funcionais, e sintomas neuropsiquiátricos em pacientes com provável doença de Alzheimer (pAD) e idosos controles. Métodos: vinte e um pDA (14 mulheres) e vinte e dois EC (16 mulheres) foram submetidos a uma bateria neuropsicológica de testes avaliando o estado cognitivo global, e funções cognitivas específicas: memória, funções executivas e atencionais, fluência verbal e habilidades visoconstrutivas. Adicionalmente, habilidades funcionais (FAQ) e sintomas neuropsiquiátricos (NPI) foram avaliados. Resultados: Teste estatístico de regressão linear indicou uma associação entre anosognosia e queixas subjetivas de memória, idade e aritmética-DRS no grupo controle. Por outro lado, aritmetica-DRS, IQCODE e FAQ (habilidades cognitivas e funcionais) foram melhores predictores nos pacientes com pDA, especificamente para consciência das alterações comportamentais. Conclusão: Os resultados indicaram que diferentes variáveis estão associadas com auto-percepção nos pacientes com pDA e controles, porém para ambos os grupos parece que o funcionamento executivo tem um papel importante contribuindo principalmente na percepção das alterações comportamentais. Palavras-chave: percepção, anosognosia, consciência, envelhecimento, doença de Alzheimer, demência.

\section{INTRODUCTION}

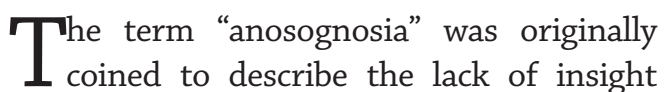
into hemiplegia following right hemisphere stroke. ${ }^{1}$ It is important to note that, whereas insight was once considered relevant only to hemiplegia, it is now recognized as applicable to cognitive and behavioral domains affected by neurological disorders other than stroke, such as dementia. ${ }^{1}$ In this article, "anosognosia" and the equivalent terms "impaired insight" and "unawareness of deficits" are used in this strict sense.

Alzheimer's disease (AD) is the most common form of dementia, and is a pathology where we can observe anosognosia symp-

IPhD, Adjunct Professor, Faculty of Ceilandia, UnB, Brasilia DF, Brazil. 2PhD, Full Professor, Laboratory of Neurosciences and Behavior, Institute of Biology, UnB, Brasilia DF, Brazil.

Corina Satler. Faculty of Ceilandia / University of Brasilia / Campus UnB Ceilandia - 72220-140 Brasilia DF - Brazil. E-mail address: satler@unb.br

Disclosure: The authors report no conflicts of interest.

Received February 18, 2012. Accepted in final form April 18, 2013. 
toms $s^{2,3}$ that can occur in up to $81 \%$ of individuals with $\mathrm{AD} .^{4}$ However, there is considerable inter-person variability in the presentation of anosognosia in $\mathrm{AD} .^{5}$

Among AD patients, studies have demonstrated that anosognosia is common in early stages of the disease, and have suggested that impairment of insight increases with severity of the dementia. ${ }^{6}$

Previous studies seeking to identify the association between awareness of cognitive deficits in $A D$ have shown mixed results. In short, the mechanisms underlying insight in $\mathrm{AD}$ remain unclear. For example, some authors ${ }^{2,5,7}$ have found a significant correlation between unawareness of deficits and global cognitive function, using the Mini-Mental State Examination (MMSE) or Clinical Dementia Rating (CDR). In contrast, other researchers have not found evidence of this association. ${ }^{8}$

In addition, some studies have also found relationships between psychiatric symptoms and anosognosia in $\mathrm{AD}^{2,7,9}$

More specifically, it has been demonstrated that there is a difference between the absence of perception of cognitive deficits and of behavioral disorders. Studies have described that $\mathrm{AD}$ patients show impaired insight for memory and cognitive deficits, and daily living activities deficits, which constitute core symptoms of $\mathrm{AD}$, but also for a range of other possible symptoms including different cognitive deficits, and psychiatric symptoms such as depression, anxiety, or irritability. ${ }^{9}$ However, there is no clear evidence that anosognosia for cognitive deficits and behavioral alterations in $\mathrm{AD}$ differs with functional and neuropsychological performance.

One example of the awareness of memory deficits in dementia is the presence of subjective memory complaints that reflect preservation of the ability to recognize and evaluate one's own deficits. Global cognitive function would be a pre-requisite for appropriate judgment. Thus, Leicht, Berwing, and Gertz ${ }^{3}$ described that while $\mathrm{AD}$ patients tended to overestimate their cognitive abilities, in older adults without cognitive impairment there is an underestimation of ability.

It has been reported that memory complaints are a feature that seem to be common among middle-aged and older adults without dementia, ${ }^{10,11}$ and that the prevalence of memory complaints tends to be higher as age increases. For example, in the Maastricht Aging Study, the prevalence of forgetfulness among volunteers was $41 \%$ in the group aged 55 to 65 years and $52 \%$ in the 70 to 85 year-old age group..$^{10}$

Jorm and colleagues ${ }^{12}$ in a community sample study, described that memory complaints were associated with poorer cognitive test performance, more prominent mood symptoms, personality characteristics and poor physical health. In other words, cognitive performance was not only contributed to by memory complaints.

In the present study, we attempted to examine the presence of lack of awareness of specific deficits (intellectual functioning and behavioral changes) in $\mathrm{AD}$ patients, and explore a possible relationship with cognitive and neuropsychiatric profiles and functional impairments.

In order to examine the presence of anosognosia in elderly adults without cognitive impairment, we also explored the relationship between awareness of deficits and cognitive performance.

\section{METHODS}

Participants. We carried out a case control study in a convenience sample of 43 participants, 21 of whom were patients diagnosed with probable $\mathrm{AD}(\mathrm{pAD})$ and 22 healthy elderly controls (EC). pAD patients were recruited from a larger pool of participants at the Geriatric Medical Center, University Hospital of Brasilia, Brasilia, Brazil, and were examined by a social worker, a neuropsychologist, and a geriatrician. Healthy controls were recruited from the community or were spouses of the patients and were examined with a comprehensive neuropsychological and neuropsychiatry evaluation, and had no history of either neurological or psychiatric disorders, including traumatic brain injury or substance abuse.

All $\mathrm{AD}$ patients met the clinical diagnostic criteria of $A D$ described by the National Institute of Neurological and Communicative Diseases and Stroke-Alzheimer's Disease and Related Disorders Association. ${ }^{13}$ The diagnoses by the study geriatricians were based on the neuropsychological, medical, and laboratory findings. The severity of $\mathrm{AD}$ ranged from mild to moderate (scores 1 or 2) according to the Clinical Dementia Rating scale. ${ }^{14}$ All patients exhibited a 1 to 4 -year history of progressive cognitive impairment, predominantly affecting memory, which was confirmed by their caregiver using the short version of the IQCODE (Informant Questionnaire on Cognitive Decline in the Elderly) ${ }^{15}$ but showed normal consciousness and lived with their families and required no special care.

All patients and control volunteers had normal or corrected-to-normal vision and hearing. The neuropsychiatric Inventory was applied to all subjects. ${ }^{16}$ If any evidence of behavior disturbance or significant depression was noted after the interview, the subject was excluded.

Instruments and procedures. After confirming the diagnosis for those patients that met the inclusion criteria 
of the study and selection of participants for the control group, the neuropsychological evaluation was performed on each individual in both groups by the same investigator. All participants were evaluated using the neuropsychological tests during two sessions on separate days (with an interval of 7 days), and tests were always applied in the same order.

Neuropsychological assessments. As part of the initial assessment, standardized neuropsychological tests were used to assess different cognitive functions.

Global Cognition Score. A Brazilian version of the MMSE, ${ }^{17}$ and the Mattis Dementia Rating Scale (DRS), was used. ${ }^{18}$ In addition, the Vocabulary subtest (the Wechsler Adult Intelligence Scale - WAIS-III $)^{19}$ was used as a measure of premorbid intelligence.

Memory. The Digit Span Forward (DRS) ${ }^{18}$ and Corsi's Block-Tapping Test ${ }^{20}$ assessed short-term memory (verbal and visual memory, respectively).

The Auditory Verbal Learning Test (RAVLT) ${ }^{21}$ was used for assessing the learning curve, strength of memory after interference task, and pattern of learning (serial positioning effects), as well as for measuring recognition memory.

The 15-item version of the Boston Naming Test (BNT) in Consortium to Establish a Registry for Alzheimer's Disease ${ }^{22}$ measured the ability to name pictures of objects (semantic memory), and the ReyOsterrieth Complex Figure (ROCF) - recall ${ }^{20}$ assessed nonverbal memory.

Executive and Attention Functions. Executive function and attention measures were assessed using the following tests: the Clock Drawing Test (CDT) - to command, ${ }^{23}$ Wisconsin Card Sort Test (WCST) - modified version, ${ }^{24}$ the Weigl Test, ${ }^{20}$ the Stroop Color-Word Test (SCWT) ${ }^{20}$ and the 5-Point Test (FPT). ${ }^{20}$ These tests evaluated planning, set shifting, selective attention, speed of visuomotor coordination, and divided attention.

Additionally, all participants performed simple arithmetic tasks (addition, multiplication, subtraction, division) using the Arithmetic subtest - DRS ${ }^{18}$ and mental manipulation of well learned sequences was assessed by the Mental Control subtest - DRS. ${ }^{18}$

Verbal Fluency. Verbal fluency tests such as Animal naming and words beginning with letters "FAS" ${ }^{20}$ were used to evaluate phonological and lexical retrieval in oral modality.
Visuoconstructive Abilities. The CDT - copy $^{23}$ and the ROCF - copy ${ }^{20}$ were used to assess visuospatial skills. In the $\mathrm{CDT}$, subjects are asked to draw a clock and to set the time at 45 past two. This task is used as a test of constructional abilities, but also requires some level of executive control.

Measure of functional abilities. These values were obtained using a questionnaire instrument filled in by an informal caregiver, such as a family member. The Pfeffer Functional Activities Questionnaire - $\mathrm{FAQ}^{25}$ was used to identify the level of functionality of the subjects required in the instrumental activities of their daily routine.

Additionally, subjective memory complaints were analyzed using a self-report memory questionnaire MAC-Q. ${ }^{26}$

Neuropsychiatric symptoms. The Neuropsychiatric Inventory (NPI) was used to measure psychopathology in the participants; this measure was also developed specifically for use with dementia. The NPI rates the severity and frequency of 12 neuropsychiatric disturbances that are common in dementia: delusions, hallucinations, agitation, dysphoria, anxiety, apathy, irritability, euphoria, disinhibition, aberrant motor behavior, night-time behavior disturbances, and appetite and eating abnormalities together with the related caregivers' distress.

Depressive mood was assessed using the Cornell Scale for Depression in Dementia (CSDD). ${ }^{27}$

As with the measures of functional abilities, the same informal caregiver was interviewed by the assessor who filled in the scales.

Anosognosia symptoms assessment. The Brazilian version of the Anosognosia Questionnaire-Dementia (AQ-D) ${ }^{28}$ was used in this study. Originally, this questionnaire was devised to examine the effects of clinical variables, such as cognitive functions and the presence of neuropsychiatric symptoms, on these domains of anosognosia in patients with $A D$.

The AQ-D is a 42-item questionnaire collecting responses from both patients and their caregivers about the current level of impairment of patients. The AQ-D consists of questions divided into two sections: The first section assesses intellectual functioning, while the second section examines changes in interests and personality. Each answer is rated as never (0 points), sometimes ( 1 point), usually ( 2 points), or always present (3 points). Thus, higher scores indicate more severe impairments. 
Form $\mathrm{A}$ is answered by the patient alone (with clarifications by the examiner if needed), whereas form $B$ (a similar questionnaire written in the third person) is answered by the patient's caregiver blind to the patient's answers in form $\mathrm{A}$.

The final score is the subtraction of scores in forms $\mathrm{A}$ from scores in form B. Thus, positive scores indicate that the caregiver rated the patient as more impaired than the patient's own evaluation (the patient was less aware of his or her cognitive and emotional deficits).

All participants were tested individually in a room with normal interior lighting.

Ethical aspects. Written, informed consent in accordance with the ethical guidelines for research with human subjects (196/96 CNS/MS resolution) was obtained from all participants and their caregivers (where appropriate). The study was approved by the Human Subject Committee of the Faculty of Medicine, University of Brasilia.

Statistical methods. A descriptive analysis (means and standard deviation) was undertaken for the socio-demographic variables of the sample. In order to evaluate the neuropsychological data, $t$ tests for independent samples were performed for each test.

Pearson's correlation coefficient was employed for correlation of scores between $A D-Q$ and the other instruments. Linear regression models were used to evaluate the association between the anosognosia scores (total score, behavioral changes score and intellectual functioning score) and the cognitive processes, the level of functionality of the subjects and neuropsychiatric symptoms.

The significance level was set at $\mathrm{p}<0.05$ (two-tailed) for all tests.

\section{RESULTS}

Socio-demographic characteristics of patients and controls are depicted in Table 1.

Mean age was 74 years (pAD patients: $78.62 \pm 6.66$ years; EC: $71.00 \pm 6.85$ years), school education was 9.62 years on average (pAD patients: $6.81 \pm 4.08$ years; EC: $12.32 \pm 4.42$ years). Groups did not differ significantly with respect to these variables [age $(\mathrm{p}=0.864)$, education $(\mathrm{p}=0.808)$ ]; however, $\mathrm{pAD}$ patients were older and had less formal education than EC.

Group performance was similar for the IQCODE test $(\mathrm{p}=0.583)$ and the MAC-Q $(\mathrm{p}=0.429)$. Notably, the scores for both groups on the MAC-Q were higher than the cut-off score ( $<25)$, (pAD patients: $26.10 \pm 5.77$; EC: $25.45 \pm 6.61)$ suggesting the presence of subjective
Table 1. Demographic characteristics in AD patients and elderly controls

\begin{tabular}{lcc}
\hline & AD $(\mathbf{n = 2 1 )}$ & EC $(\mathbf{n = 2 2})$ \\
\hline Age (years) & $78.62 \pm 6.66$ & $71.00 \pm 6.85$ \\
\hline Range & $65-88$ & $65-84$ \\
\hline Gender (M:F) & $7: 14$ & $8: 16$ \\
\hline Education level (years) & $6.81 \pm 4.08$ & $12.32 \pm 4.42$ \\
\hline Range & $15-04$ & $12-04$ \\
\hline FAQ** & $19.19 \pm 7.27$ & $0.32 \pm 1.04$ \\
\hline NPI total score* & $17.33 \pm 12.09$ & $6.23 \pm 7.45$ \\
\hline CSDD total score* & $10.33 \pm 6.91$ & $5.50 \pm 3.88$ \\
\hline IQCODE score & $3.90 \pm 0.60$ & $2.88 \pm 0.52$ \\
\hline MAC-Q score & $26.10 \pm 5.77$ & $25.45 \pm 6.61$ \\
\hline AQ-D cognitive changes score ${ }^{\star *}$ & $25.48 \pm 16.15$ & $5.45 \pm 7.72$ \\
\hline AQ-D behavioral changes score* & $8.81 \pm 10.31$ & $3.23 \pm 5.74$ \\
\hline AQ-D total score ${ }^{\star \star}$ & $34.76 \pm 24.77$ & $8.95 \pm 12.25$ \\
\hline
\end{tabular}

AD: Alzheimer's disease; EC: Elderly controls; M:F: Male:Female; FAQ: Functional Activities Questionnaire; NPI: Neuropsychiatric Inventory; CSDD: Cornell Scale for Depression in Dementia; IQCODE: Informant Questionnaire on Cognitive Decline in Elderly; MAC-Q: Memory Complaint Questionnaire; AQ-D: Anosognosia Questionnaire for Dementia. Values expressed as means $\pm S D$ or Percentage. ${ }^{*} p<0.05 ;{ }^{* *} p<0.01$ (Student's t-test).

memory complaints. Additionally, it is also important to note that the $\mathrm{pAD}$ patients showed higher scores on the CSDD compared to EC ( $\mathrm{p}=0.009)$.

Neuropsychological assessment. Neuropsychological results are listed in Table 2 and revealed a significant main difference among EC and pAD patients which reached statistical significance on most tests except the 5-Point Test-perseverations $(\mathrm{p}=0.713)$. In general, $\mathrm{t}$ tests showed that $\mathrm{pAD}$ patients performed significantly worse than EC.

$A Q-D$ Intellectual functioning. The performance of the $\mathrm{AD}$ group on two cognitive tests (DRS - total and FPT unique designs) was inversely associated with the degree of anosognosia $(r(2)=0.748 ; p<0.001)$, which explained $51.1 \%$ of the variance (DRS - total score: $42.1 \%$ and FPT - unique designs: $9 \%$ ). Additionally, two other variables contributed positively to the increase of anosognosia symptoms: Letter FAS (15.8\%) and NPI (7.9\%). For the EC group, MAC-Q score and age variables were inversely associated with degree of anosognosia $(\mathrm{R}(2)=0.38$; $\mathrm{p}=$ 0.004 ), explaining $38 \%$ of the variance (MAC-Q: $26.2 \%$ and age: $12.2 \%$ ) (Table 3 ).

$A Q-D$ behavior changes. In the $\mathrm{AD}$ group, cognitive and functional abilities were associated with degree of anosognosia $(R(2)=0.835 ; \mathrm{p}<0.001)$, which explained 
Table 2. Test performance of $A D$ patients and elderly controls.

\begin{tabular}{|c|c|c|}
\hline Measure & AD & EC \\
\hline \multicolumn{3}{|l|}{ Global cognition score } \\
\hline MMSE, n/ 30** & $18.00 \pm 4.29$ & $28.64 \pm 1.39$ \\
\hline DRS, n/ 144* & $113.33 \pm 8.45$ & $139.27 \pm 3.70$ \\
\hline Vocabularysubtest (WAIS-R) ${ }^{\star \star}$ & $32.48 \pm 10.14$ & $49.27 \pm 8.33$ \\
\hline \multicolumn{3}{|l|}{ Short-term memory } \\
\hline Digit Span Forward (DRS) ${ }^{\star \star}$ & $4.95 \pm 1.32$ & $6.64 \pm 1.13$ \\
\hline Corsi' Block-TappingTest Forward* & $4.81 \pm 1.91$ & $6.50 \pm 1.94$ \\
\hline \multicolumn{3}{|l|}{ Episodic recall } \\
\hline \multicolumn{3}{|l|}{ RAVLT } \\
\hline Trial 1 & $2.00 \pm 1.61$ & $5.45 \pm 1.43$ \\
\hline Trial 2 & $2.90 \pm 2.09$ & $7.77 \pm 1.82$ \\
\hline Trial 3 & $3.38 \pm 2.24$ & $9.59 \pm 2.42$ \\
\hline Trial 4 & $3.76 \pm 2.11$ & $9.72 \pm 1.93$ \\
\hline Trial 5 & $4.04 \pm 2.65$ & $11.00 \pm 1.87$ \\
\hline Delayed Recall & $0.95 \pm 2.15$ & $8.36 \pm 2.40$ \\
\hline Delayed Recognition & $-9.38 \pm 14.05$ & $10.86 \pm 3.50$ \\
\hline \multicolumn{3}{|l|}{ Semantic recall } \\
\hline BNT, n/ 15 & $12.48 \pm 2.13$ & $15 \pm 0.00$ \\
\hline \multicolumn{3}{|l|}{ Nonverbal recall } \\
\hline ROCF - Recall ${ }^{\star \star}$ & $3.00 \pm 3.13$ & $18.00 \pm 6.10$ \\
\hline \multicolumn{3}{|l|}{ Working Memory } \\
\hline Digit Span Backward (DRS) ${ }^{\star \star}$ & $2.62 \pm 1.39$ & $4.41 \pm 1.18$ \\
\hline Corsi' Block Test Backward** & $2.81 \pm 1.53$ & $5.23 \pm 1.27$ \\
\hline \multicolumn{3}{|l|}{ Calculation ability } \\
\hline Arithmeticsubtest (DRS)** & $3.33 \pm 0.61$ & $7.50 \pm 0.85$ \\
\hline \multicolumn{3}{|l|}{ Executive and Attention functions } \\
\hline CDT - To command** & $7.38 \pm 2.51$ & $9.82 \pm 0.50$ \\
\hline WCST - Categories ${ }^{\star \star}$ & $1.57 \pm 1.59$ & $4.05 \pm 1.67$ \\
\hline WCST - Total errors ${ }^{\star \star}$ & $20.14 \pm 12.28$ & $7.27 \pm 5.74$ \\
\hline FPT - Unique designs ${ }^{\star \star}$ & $5.19 \pm 4.39$ & $18.41 \pm 7.71$ \\
\hline FPT - Perseverations, $\%$ & $2.43 \pm 2.78$ & $2.14 \pm 2.37$ \\
\hline StroopTest - Interference condition,n/32** & $13.95 \pm 8.05$ & $27.27 \pm 5.60$ \\
\hline Mental Control subtest (DRS) ${ }^{\star *}$ & $5.29 \pm 2.77$ & $8.68 \pm 0.64$ \\
\hline \multicolumn{3}{|l|}{ Verbal Fluency } \\
\hline Letters $(\text { FAS) })^{\star \star}$ & $16.86 \pm 10.05$ & $36.45 \pm 10.63$ \\
\hline Categories (animal) & $5.57 \pm 2.74$ & $17.77 \pm 4.33$ \\
\hline \multicolumn{3}{|l|}{ Visuoconstructive abilities } \\
\hline CDT - copy ${ }^{\star \star}$ & $4.57 \pm 2.95$ & $9.55 \pm 0.85$ \\
\hline ROCF - copy ${ }^{\star \star}$ & $19.12 \pm 12.13$ & $33.5 \pm 2.63$ \\
\hline
\end{tabular}

AD: Alzheimer's disease; EC: Elderly controls; MMSE: Mini-Mental State Examination; DRS: Mattis Dementia Rating Scale; RAVLT: Rey's auditory verbal learning test, trial 1 - trial 5 , delayed recall score is the number of words reproduced from the 15 words given, recognition range 0 - 30 (score of 15 is chance and 30 indicates complete recognition);50 BNT: Boston Naming test; ROCF: Rey-Osterrieth Complex Figure; CDT: Clock Drawing test; WCST: Wisconsin Card Sorting test; FPT: Five-Point test. Values expressed as means $\pm S D .{ }^{*} p<0.05 ;{ }^{* *} p<0.01$ (Student's t-test). Higher test scores indicate better performances. 
$83.5 \%$ of the variance (IQCODE test: $44.1 \%$, FAQ: $19 \%$, Arithmetic subtest: 19\%, Stroop test - interference condition: $3.7 \%$, and RAVLT- delayed recall: $5.2 \%$ being inversely proportional). For the EC group, performance on two cognitive tasks (Arithmetic subtest-DRS and Mental control subtest - DRS) was associated with the presence of anosognosia symptoms focused on behavior changes $(R(2)=0.403 ; p=0.003)$. Both cognitive variables explained $40.3 \%$ of the variance (Arithmetic subtest - DRS: 27.3\% and Mental control subtest - DRS: 13\%) (Table 3). $A Q-D$ total score. In the $\mathrm{AD}$ group, cognitive and functional abilities scores were associated with degree of anosognosia $(\mathrm{R}(2)=0.821 ; \mathrm{p}<0.001)$, which explained $80 \%$ of the variance (IQCODE test: $38.8 \%$, FAQ: $23.4 \%$,
Arithmetic subtest - DRS: $13.6 \%$ and BNT: 6.3\%; where the latter variable was inversely proportional to the presence of anosognosia symptoms) (Table 3).

For the EC group, three variables were associated with the presence of anosognosia symptoms $(\mathrm{R}(2)=$ $0.572 ; \mathrm{p}<0.001$ ), which explained $57.2 \%$ of the variance: Arithmetic subtest - DRS (29.9\%), MAC-Q (16.8\%) and age (10.5\%). Two of these variables, MAC-Q and age, were inversely proportional to anosognosia symptoms (Table 3).

\section{DISCUSSION}

The aim of this study was to explore a possible relationship between the presence of anosognosia symptoms

Table 3. Significant variables associated with anosognosia symptoms.

\begin{tabular}{|c|c|c|c|c|c|c|c|c|c|}
\hline & & b & EP & $\mathbf{T}$ & p-value & $\mathbf{R} 2$ & $\mathbf{F}$ & gl & p-value \\
\hline \multicolumn{10}{|c|}{ AQ-D Intellectual Functioning } \\
\hline \multirow[t]{3}{*}{ EC } & Constant & 56.53 & 16.52 & 3.42 & 0.003 & \multirow{3}{*}{0.38} & \multirow{3}{*}{7.55} & \multirow{3}{*}{2.19} & \multirow{3}{*}{0.004} \\
\hline & MAC-Q & -0.76 & 0.21 & -3.67 & 0.002 & & & & \\
\hline & Age & -0.45 & 0.20 & -2.22 & 0.038 & & & & \\
\hline \multirow[t]{5}{*}{ AD Patients } & Constant & 200.80 & 28.88 & 6.96 & $<0.001$ & \multirow{5}{*}{0.75} & \multirow{5}{*}{15.85} & \multirow{5}{*}{4.16} & \multirow{5}{*}{$<0.001$} \\
\hline & DRS total score & -1.66 & 0.28 & -6.02 & $<0.001$ & & & & \\
\hline & FPT - Unique designs & -1.65 & 0.45 & -3.65 & 0.002 & & & & \\
\hline & Letters (FAS) & 0.86 & 0.24 & 3.61 & 0.002 & & & & \\
\hline & NPI & 0.38 & 0.15 & 2.51 & 0.023 & & & & \\
\hline \multicolumn{10}{|c|}{ AQ-D Behavior changes } \\
\hline \multirow[t]{3}{*}{ EC } & Constant & -55.62 & 15.87 & -3.50 & 0.002 & \multirow{3}{*}{0.4} & \multirow{3}{*}{8.10} & \multirow{3}{*}{2.19} & \multirow{3}{*}{0.003} \\
\hline & Arithmetic subtest (DRS) & 3.82 & 1.12 & 3.39 & 0.003 & & & & \\
\hline & Mental Control subtest (DRS) & 3.48 & 1.50 & 2.32 & 0.032 & & & & \\
\hline \multirow[t]{6}{*}{ AD Patients } & Constant & -63.35 & 8.80 & -7.20 & $<0.001$ & \multirow{6}{*}{0.83} & \multirow{6}{*}{21.31} & \multirow{6}{*}{5.15} & \multirow{6}{*}{$<0.001$} \\
\hline & Arithmetic subtest (DRS) & 2.20 & 0.42 & 5.29 & $<0.001$ & & & & \\
\hline & IQCODE & 12.33 & 2.01 & 6.11 & $<0.001$ & & & & \\
\hline & $\mathrm{FAQ}$ & 0.72 & 0.15 & 4.86 & $<0.001$ & & & & \\
\hline & RAVLT - delayed recall & -1.29 & 0.52 & -2.47 & 0.026 & & & & \\
\hline & Stroop - interference cond. & 0.30 & 0.14 & 2.15 & 0.048 & & & & \\
\hline \multicolumn{10}{|c|}{ AQ-D Total score } \\
\hline \multirow[t]{4}{*}{ EC } & Constant & 42.11 & 32.22 & 1.31 & 0.208 & \multirow{4}{*}{0.572} & \multirow{4}{*}{10.36} & \multirow{4}{*}{3.18} & \multirow{4}{*}{$<0.001$} \\
\hline & Arithmetic subtest (DRS) & 5.33 & 2.18 & 2.45 & 0.025 & & & & \\
\hline & MAC-Q & -1.05 & 0.29 & -3.63 & 0.002 & & & & \\
\hline & Age & -0.65 & 0.28 & -2.38 & 0.029 & & & & \\
\hline \multirow[t]{5}{*}{ AD Patients } & Constant & -41.33 & 32.20 & -1.28 & 0.217 & & & & \\
\hline & Arithmetic subtest (DRS) & 4.10 & 0.97 & 4.25 & 0,001 & & & & \\
\hline & IQCODE & 17.55 & 4.90 & 3.58 & 0.002 & 0.821 & 23.96 & 4.16 & $<0.001$ \\
\hline & $F A Q$ & 2.05 & 0.34 & 6.04 & 0,000 & & & & \\
\hline & BNT & -3.65 & 1.37 & -2.65 & 0.017 & & & & \\
\hline
\end{tabular}

AD: Alzheimer's disease; EC: Elderly controls; AQ-D: Anosognosia Questionnaire in Dementia; MAC-Q: Memory Complaint Questionnaire; DRS: Mattis Dementia Rating Scale; FPT: Five-Point test; NPI: Neuropsychiatric Inventory; IQCODE: Informant Questionnaire on Cognitive Decline in Elderly; FAQ: Functional Activities Questionnaire; RAVLT: Rey's auditory verbal learning test; BNT: Boston Naming test. 
and cognitive domains, functional abilities, and neuropsychiatric symptoms in $\mathrm{pAD}$ patients and normal elderly controls.

The main finding of this study was a significant difference between groups regarding the presence of anosognosia symptoms. Results showed that $\mathrm{pAD}$ patients were less accurate in evaluating the level of their awareness of cognitive and behavioral changes than healthy older adults, as evidenced by a larger discrepancy between self-and informant ratings on the AQ-D in pAD patients compared to EC. These findings corroborate a long line of research that suggests the presence of anosognosia for cognitive deficits and behavioral changes is a common and early feature of AD. ${ }^{7}$

AD patients and anosognosia. Examining awareness of intellectual functioning, results showed a strong association with global cognitive functioning (DRS - total score). A similar result has been described by Sato and colleagues ${ }^{29}$ using the same anosognosia questionnaire (AD-Q), and the MMSE as a screening test for dementia. Thus, our findings showing that preserved awareness was associated with more intact cognitive functioning supports previous research. $2,6,7,30$

Furthermore, the association between verbal and design fluency tasks (FAS test and FPT respectively) with intellectual awareness suggests that $\mathrm{pAD}$ patients who have poor executive functioning might show more anosognosia for intellectual deficits, as described by other studies, ${ }^{31}$ including an association with specific brain alterations such as those involving frontal lobe regions. ${ }^{32}$

Loss of awareness, as well as psychosis and apathy, has been associated with neuropsychological changes in right frontal and related subcortical structures. ${ }^{4}$ Similarly, our findings showed a modest association between awareness for cognitive deficits and the NPI suggesting that $\mathrm{PAD}$ patients with behavioral disturbances failed to appreciate the degree of their cognitive impairment and often under-estimated it.

Levels of unawareness of behavioral changes were associated with higher scores on the IQCODE. These findings suggested that $\mathrm{PAD}$ patients with impaired insight were described by their caregivers and family members as having more cognitive changes over the last 10 years.

We also found an association between behavioral awareness and functional abilities (FAQ), a finding also described by previous studies. ${ }^{29,33}$ This association suggests that patients with a higher level of independence have more insight about self-care, in contrast to patients that exhibit functional impairment.
pAD patients with functional impairment are unable to perform some complex tasks, such as cooking, managing their finances, shopping, using the telephone, and taking medications. Considering that these activities require a greater variety of cognitive abilities, usually involving higher order cognitive processes, ${ }^{34}$ several studies have described that cognitive impairment is strongly associated with alterations in IADL. ${ }^{35,36}$ Along the same lines, Barberger-Gateau and colleagues ${ }^{37}$ found a relationship between performance on neuropsychological tests and measures of IADL and high risk for developing dementia.

In addition, our findings showed that results on neuropsychological tests were associated with loss of awareness of behavioral problems, namely, math skills such as numerical and calculation tasks (Arithmetic subtest - DRS), attention and response inhibition (Stroop test), and delayed recall of word-list (RAVLT - delayed recall).

In the area of arithmetic, there are differences in the strategies people use to solve an arithmetic problem. For example, the same person might solve a simple subtraction problem by counting and solve another by retrieving the answer from memory. ${ }^{38}$ Arithmetic fact retrieval is very likely to involve lexical processes, in that arithmetic facts appear to be represented in the same memory system that supports world retrieval, called "semantic memory". Thus, according to the literature, multiplication sums such as $3 \times 4=12$ are assumed to be stored in long-term memory. ${ }^{39}$

In addition, several studies have shown the role of the prefrontal cortex in mathematical performance, particularly in actual mathematical calculation or reasoning. ${ }^{40}$ In school-age children and adolescents, mathematical skills are associated with executive functions ${ }^{41}$, and Bull and Scerif ${ }^{42}$ have also noted the role of specific executive functions, such as working memory and inhibition in mathematical proficiency.

In the Stroop test, the incongruent condition consists of naming the color of ink in which a color name is printed when the color is incongruent with the name. This condition elicits the Stroop effect that implies a significant slowing of performance. The response tendency or task set of reading the word, through life-long experience with reading is initially activated more strongly than the novel response tendency or task set naming the color. A number of studies have shown a deficit in Stroop test performance by patients with $\mathrm{pAD}$, and evidence suggests that this deficit is due to a breakdown in inhibitory processes that occurs early in the course of the disease. ${ }^{43}$ These results are in line with those obtained by other studies suggesting that pathology for 
frontal brain regions is typically associated with executive dysfunction and also with poor behavioral insight. ${ }^{44}$

It is also found that episodic memory impairments (word recall - RAVLT) are associated with an increase in behavioral awareness. Difficulty with the acquisition of new information is generally the first and most salient symptom to emerge in patients with pAD. Studies describe the loss of episodic memory as the core feature of the dementing processes, ${ }^{45}$ and these observations are consistent with findings that brain structures known to be critical to episodic recall, such as the hippocampus and neighboring regions, show pathological alterations in $\mathrm{pAD}$ patients..$^{46,47}$ In addition, there is evidence that the delayed recall score of word-list learning tasks, such as RAVLT, is the best neuropsychological parameter for discriminating $\mathrm{pAD}$ patients from healthy controls. ${ }^{48}$

Previous studies have described an association between anosognosia and behavioral changes in $\mathrm{pAD}$ patients, and have correlated the lack of awareness of their deficits with disease progress, and marked cognitive and functional impairment. ${ }^{2,5,30}$

Despite the relative lack of awareness of the severity of everyday cognitive declines and behavioral changes (total score in $\mathrm{AD}-\mathrm{Q}$ ), our findings showed that the same main factors that specifically contributed to behavioral awareness (IQCODE, FAQ, and Arithmetic subtest DRS), were also associated with general anosognosia, suggesting that behavioral changes tend to be a better predictor of anosognosia in $\mathrm{AD}$ patients.

Regarding a possible association between anosognosia and symptoms of depressed mood in $\mathrm{AD}$ patients, our results showed that the lack of awareness of their deficits is not influenced by the presence of depressed symptoms, as described by another studies. ${ }^{2,4,28,30}$

Elderly controls and anosognosia. In the evaluation of elderly controls, there was a negative association between awareness for intellectual functioning and subjective memory complaints. Consequently, those elderly that reported subjective memory complaints seemed able to pay attention to their own cognitive functioning and exhibit preservation in self-awareness.

These findings are in agreement with previous studies describing that memory complaints are frequent in healthy elderly population..$^{11,49}$ However, given performancelevels of these participants on neuropsychological tests were according to their age and educational level, it can be said that participants' complaints of memory are not an accurate reflection of real memory disturbance. Thus, it seems the over-estimation in healthy Brazilian elders may be related to cultural factors.

Regarding awareness of behavioral changes, our findings showed that math skills (Arithmetic subtest - DRS) and executive control (Mental control subtest - DRS) were associated with awareness of behavioral problems, suggesting executive functions are involved in this process. Although elderly controls did not exhibit high anosognosia scores, an interesting pattern was observed similar to that observed in $\mathrm{PAD}$ patients.

When analyzing total scores, the variables that contributed to intellectual functioning and behavioral changes were associated with general anosognosia. The findings differ in this regard from the general pattern observed in $\mathrm{pAD}$ patients where mainly behavioral changes contributed to general anosognosia.

Considered as a whole, we found that different variables were associated with self-awareness for $\mathrm{pAD}$ patients and elderly controls, but for both groups it seems that executive functions play an important role in contributing to awareness of behavioral changes.

Our findings in this report are subject to at least four limitations. First, data on the educational level of relatives or proxies were not collected, and this point should be addressed in further studies since this may have influenced the IQCODE results. Second, the diagnosis of anosognosia was based on cut-off scores on a severity rating scale rather than on valid diagnostic criteria for anosognosia. Third, this study investigated awareness deficits in pAD patients considering discrepancies between informant and self-reports in order to establish anosognosia. Although this approach can be valid when shown to correspond to objective performance, it is potentially influenced by informants' personal characteristics and prone to inaccuracy, as reported by Zanetti and colleagues. ${ }^{50}$ Finally, the small sample size is a shortcoming that limits this study, and any conclusion should be interpreted with caution. Therefore, further studies, including larger samples of controls and $\mathrm{pAD}$ patients, as well as other neuropsychological tests, are necessary to assess the association with awareness of deficits in the early stage of $\mathrm{AD}$.

Acknowledgements. The authors would like to thank Dr. Carlos Uribe for assistance with statistical analysis. This study was supported by FINATEC. No author has any conflict of interest relating to this article. 


\section{REFERENCES}

1. McGlynn S, Schacter D. Unawareness of deficits in neuropsychological syndromes. J Clin Exp Neuropsychol 1989;11:143-205.

2. Derouesné C, Thibault S, Lagha-Pierucci S, Baudouin-Madec V, Ancri D, Lacomblez L. Decreased awareness of cognitive deficits in patients with mild dementia of the Alzheimer type. Int J Geriatr Psychiatry 1999;14:1019-1039.

3. Leicht H, Berwig M, Gertz H. Anosognosia in Alzheimer's disease: the role of impairment levels in assessment of insight across domains. J Int Neuropsychol Soc 2010;16:463-473.

4. Reed B, Jagust W, Coulter L. Anosognosia in Alzheimer's disease: Relationships to depression, cognitive function, and cerebral perfusion. J Clin Exp Neuropsychol 1993;15:231-244.

5. Lamar M, Lasarev M, Libon D. Determining levels of unawareness in dementia research. J Neuropsychitry Clin Neurosci 2002;14:430-436.

6. Berwig M, Leicht $\mathrm{H}$, Gertz $\mathrm{H}$. Critical evaluation of self-rated quality of life in mild cognitive impairment and Alzheimer's disease-further evidence for the impact of anosognosia and global cognitive impairment. J Nutr health Aging 2009;13:226-230.

7. Harwood D, Sultzer D, Wheatley M. Impaired insight in Alzheimer disease: Association with cognitive deficits, psychiatric symptoms and behavioral disturbances. Neuropsychiatry, Neuropsychol Behav Neurol 2000;13:83-88.

8. Seltzer B, Vasterling J. Awareness of deficit in Alzheimer's disease: Association with psychiatric symptoms and other disease variables. J Clin Geropsychol 1995;1:79-87.

9. Starkstein S, Sabe L, Chemerinski E, Jason L, Leiguarda R. Two domains of anosognosia in Alzheimer's disease. J Neurol Neurosurg Psychiatry 1996;61:485-490.

10. Ponds R, Commissaris K, Jolles J. Prevalence and covariates of subjective forgetfulness in a normal population in the Netherlands. Int J Aging Hum Dev 1997;45:207-221.

11. Ginó S, Mendes T, Maroco J, et al. Memory complaints are frequent but qualitatively different in young and elderly healthy people. Gerontology 2010;56:272-277.

12. Jorm A, Butterfield B, Anstey $\mathrm{K}$, al e. Memory complaints in a community sample aged 60-64 years: associations with cognitive functioning, psychiatric symptoms, medical conditions, APOE genotype, hippocampus and amygdala volumes, and whiter-matter hyperintensities. Psychol Med 2004;34:1495-1506.

13. McKhann G, Drachman D, Folstein M, Katzman R, Price D, Stadlan E. Clinical diagnosis of Alzheimer's disease. Report of the NINCDSADRDA work group under the auspices of Department of Health and Human Services Task Force on Alzheimer's disease. Neurology 1984; 34:939-944

14. Hughes C, Berg L, Danziger W, Coben L, Martin R. A new clinical scale for the staging of dementia. Br J Psychiatry 1982;140:566-572.

15. Jorm A. A short-form of the Informant Questionnaire on Cognitive Decline in the Elderly (IQCODE): development and cross-validation. Psychol Med 1994;24:145-153.

16. Cummings J, Mega M, Gray K, Rosenberg-Thompson S, Carusi D, Gornbein J. The Neuropsychiatric Inventory: comprehensive assessment of psychopathology in dementia. Neurology 1994;44:2308-2314.

17. Bertolucci P, Brucki S, Campacci S, Juliano Y. O Mini-exame do Estado Mental em uma população geral: impacto da escolaridade. Arq Neuropsiquiatr 1994;52:1-7

18. Porto C, Charchat Fichman H, Caramelli P, Bahia V, Nitrini R. Brazilian version of the Mattis Dementia Rating Scale. Arq Neuropsiquiatr 2003;61:339-345

19. Wechsler D. WMS-III Administration and Scoring Manual. San Antonio, Tx: The Psychological Corporation; 1997.

20. Spreen O, Strauss E. A compendium of neuropsychological tests. New York: Oxford University Press; 1998.

21. Rey A. L'Examen psychologique dans le cas d'encephalo-pathic traumatique. Arch Psychol 1942;28:286-340.

22. Morris J, Heyman A, Mohs R, et al. The Consortium to Establish a Registry for Alzheimer's Disease (CERAD). Part I. Clinical and neuropsychological assessment of Alzheimer's disease. Neurology 1989;39:1159-1165.

23. Royall D, Cordes J, Polk M. CLOX: an executive clock drawing task. J Neurol Neurosurg Psychiatry 1998;64:588-594.

24. Zubicaray G, Smith G, Ghalk J, Semple J. The modified Card Sorting Test: test-retest stability and relationships with demographic variables in a healthy older adult sample. Br J Psychiatry 1998;37:457-466.

25. Pfeffer R, Kurosaki T, CH H, Chance J, Filos S. Measurement of functional activities in older adults in the community. J Gerontology 1982;37:323-329.
26. Mattos P, Lino V, Rizo L, Alfano A, Araujo C, Raggio R. Memory complains and test performance in health elderly persons. Arq Neuropsiquiatr 2003;61:920-924.

27. Alexopoulos G, Abrams R, Young R, Shamoian C. Cornell Scale for Depression in dementia. Biol Psychiatry 1988;23:271-284.

28. Almeida $\mathrm{O}$, Crocco E. Percepção dos déficits cognitivos e alterações do comportamento em pacientes com Doença de Alzheimer. Arq Neuropsiquiatr 2000;58:292-299.

29. Sato J, Nakaaki S, Murata Y, et al. Two dimensions of anosognosia in patients with Alzheimer's disease: reliability and validity of the Japanese version of the Anosognosia Questionnaire for Dementia (AQ-D). Psychiatry Clin Neurosci 2007;61:672-677.

30. Lopez O, Becker J, Somsak D, Dew M, DeKosky S. Awareness of cognitive deficits and anosognosia in probable Alzheimer's disease. Eur Neurol 1994;34:277-282.

31. Starkstein S, Sabe L, Garcia Cuerva A, Kuzis G, Leiguarda R. Anosognosia and procedural learning in Alzheimer's disease. Neuropsychiatry, Neuropsychol Behav Neurol 1997;10:96-101

32. Ecklund-Johnson E, Torres I. Unawereness of deficits in Alzheimer's disease and other dementias: Operational definitions and empirical findings. Neuropsychol Rev 2005;15:147-166.

33. Starkestein S, Jorge R, Mizrahi R, Robinson R. A diagnostic formulation for anosognosia in Alzheimer's disease. J Neurol, Neurosurgy Psychiatry 2006;77:719-725.

34. Stout J, Wyman M, Johnson S, Peavy G, Salmon D. Frontal behavioral syndromes and functional status in probable Alzheimer disease. Ame J Geriatr Psychiatry 2003;11:683-686.

35. Dodge H, Shen C, Pandav R, DeKosky S, Ganguli M. Functional transitions and active life expectancy associated with Alzheimer disease. Arch Neurol 2003:60:253-259.

36. Monaci L, Morris R. Neuropsychological screening performance and the association with activities of daily living and instrumental activities of daily living in dementia: baseline and 18- to 24- month follow-up. Int J Geriatr Psychiatry 2011;27:197-204.

37. Barberger-Gateau P, Fabriogule C, Rouch I, Letenneur L, Dartigues J. Neuropsychological correlates of self-reported performance in instrumental activities of daily living and prediction of dementia. J Gerontology 1999;54B:293-303.

38. Geary D. Mathematical disabilities: Cognitive, neuropsychological, and genetic components. Psychol Bull 1993;114:345-362.

39. Rickard T. A revised identical elements model of arithmetic fact representation. J Exp Psychol: Learn Mem Cogn 2005;31:250-257.

40. Zago L, Pesenti M, Mellet E, Crivello F, Mazoyer B, Tzourio-Mazoyer N. Neural correlates of simple and complex mental calculation. Neuroimage 2001;13:314-327.

41. Cirino P, Morris M, Morris R. Neuropsychological concomitants of calculation skills in college students referred for learning difficulties. Dev Neuropsychol 2002:21:201-218.

42. Bull R, Scerif G. Executive functioning as a predictor od children's mathematics ability: Inhibition, switching, and working memory. Dev Neuropsychol 2001;19:273-293.

43. Spieler D, Balota D, Faust M. Stroop Performance in Healthy Younger and Older Adults and in Individuals With Dementia of the Alzheimer's Type. J Exp Psychol Hum Percept Perform 1996;22:461-479.

44. Bach L, David A. Self-Awareness after acquired and traumatic brain injury. Neuropsychol Rehabil 2006;16:397-414.

45. Small B, Fratiglioni L, Viitanen M, Winblad B, Bäckman L. The course of cognitive impairment in preclinical Alzheimer disease: three- and 6-year follow-up of a population-based sample. Arch Neurol 2000;57: 839-844.

46. Braak H, Braak E. Neuropathological staging of Alzheimer-related changes. Acta Neuropathol 1991;82:239-259.

47. Nyberg L, Mclntosh A, Houle S, Nilsson L, Tulving E. Activation of medial temporal structures during episodic memory retrieval. Nature 1996;380:715-717

48. Becker J, Overman A. The memory deficit in Alzheimer' Disease. In: Baddeley A, Kopelman M, Wilson B, eds. The handbook of memory disorders: John Wiley \& Sons Ltd, 2002: 569-589.

49. Jonker C, Geerlings M, Schmand B. Are memory complaints predictive for dementia? A review of clinical and population- based studies. Int $J$ Geriatric Psychiatr 2000;15:983-991.

50. Zanetti O, Vallotti B, Frisoni G, et al. Insight in dementia: When does it occur? Evidence for a non-linear relationship between insight and cognitive status. J Gerontology 1999;54:100-107. 